\title{
FOSTERING RETENTION IN ONLINE HIGHER EDUCATION: STUDENTS' PERCEPTIONS OF AN INTERVENTION ADDRESSING THEIR FIRST-YEAR EXPERIENCE
}

\author{
Marlon Xavier, Julio Meneses, Universitat Oberta de Catalunya (UOC), Spain
}

\begin{abstract}
Dropout represents one of the greatest challenges faced by online higher education. This paper presents an institutional intervention aimed at fostering retention and success of first-year undergraduate students at the Universitat Oberta de Catalunya (UOC), an online and open University, through measures addressing learning design and academic support. Secondly, through analysing in-depth interviews with first-year students, the paper explores their perception of intervention measures and their possible advantages or risks. Results indicate that time-related factors represent the major issue for persistence and continuance. Intervention measures such as personalized course packages which prevent overlapping of submission deadlines; flexibility in continuous assessment; and personalized support and academic advising were valued highly by most students. Future retention interventions in open universities are also discussed.
\end{abstract}

\section{Introduction}

\section{Dropout and Retention in Online Higher Education}

Dropout represents one of the greatest challenges faced by online educators and administrators (Lee \& Choi, 2011), as online higher education (OHE) tends to present higher dropout and lower retention rates than traditional face-to-face education (Muljana \& Luo, 2019). Early dropout is typical of OHE programs, sometimes reaching 50\% of firstyear students (Simpson, 2010). Many studies have investigated the factors that influence dropout and retention. Reviewing key dropout factors, Lee and Choi (2011) found that among the most important ones were student factors such as academic background and skills, self-efficacy, and motivation; course and program factors like course design and institutional support; and environmental factors such as work situation, family and job support, and life circumstances. 
However, more broadly speaking, lack of time and time-related conflicts seem to be the main factors that lead to dropout (McNeill, 2010; Xavier \& Meneses, 2018). That seems to be due to two key issues (Korstange, Hall, Holcomb, \& Jackson, 2020). On the one hand, students' misconceptions or unrealistic expectations regarding the workload, time, effort, discipline, and involvement required by OHE (Bawa, 2016), and overestimation of their own readiness, available time, and capacities. On the other hand, time-related issues such as time management to deal effectively with OHE demands and job and family commitments are essential for success and persistence (Michinov, Brunot, Le Bohec, Juhel, \& Delaval, 2011) while procrastination, lack of time, and conflicting work-study-life demands are key factors for dropout (Ashby, 2004; Youkselturk \& Inan, 2006).

In that sense, first- and second-semester enrolments play a crucial role. Slim, Heileman, Al-Doroubi, and Abdallah (2016) found that course enrolment has a profound impact on student achievement and engagement at both course and semester levels. Many students overestimate their capacities and time-availability and underestimate what is required by OHE; thus, they often enrol in too many or too difficult courses, sometimes with overlapping schedules, and end up dropping out in their first semester or year - sometimes from their courses but also from the degree.

\section{Context of Intervention and Research}

Both the intervention and the research reported herein were carried out at the Universitat Oberta de Catalunya (UOC). As an open, fully university, UOC is characterized by flexibility: there are no permanence requirements and very few enrolment requirements, and access is very open. Although flexibility is seen as the main attraction of OHE (Soffer, Kahan, \& Nachmias, 2019), especially for busy, time-poor adult students, it also increases individual responsibility, for eLearning is mostly self-directed and self-regulated. UOC's typical students are non-traditional learners: mature-aged or adult, with full- or part-time jobs and/or family responsibilities. Statistically, $40.5 \%$ of students are 30 or over, and $81.5 \%$ study and work; dropout rate at UOC is $57.6 \%$, with first semester drop-outs accounting for nearly half of this total (Grau-Valldosera, Minguillón, \& Blasco-Moreno, 2018). The combination of paid work alongside studies is related to dropout (Hovdhaugen, 2015), as it may create conflicting commitments and time constraints.

Regarding enrolment, at UOC students choose freely which courses they want to take each semester, guided by an academic advisor who offers recommendations. Learning design at UOC is characterized by the employment of continuous assessment (CA), of a diagnostic, formative, and summative character. To pass a course (completion), students are usually required to pass all the evaluation activities plus a synthesis test at the end of the semester. That implies that successfully adhering to CA is the best predictor for re-enrolment. Hence, 
students who withdraw from the CA process (i.e. not submitting activities) are most likely to drop out of a course (González, Minguillón, Martínez-Aceituno, \& Meneses, 2018).

Therefore, in order to foster retention, persistence, and satisfaction, institutional support must address students' first and second enrolments (i.e. their selection of courses and academic pathways), balancing through academic advising their expectations and goals with their time availability and previous academic results, as well as providing students with flexibility in the CA process during their first academic year so as to be able to face unexpected situations (González et al., 2018).

Thus, the aim of this paper is, firstly, to present an institutional intervention that seeks to address these issues, and secondly to characterize the participant students and explore their perception of its measures and their possible advantages or risks.

\section{The ESPRIA Intervention}

UOC's ongoing institutional project First-year Students (ESPRIA, for its initials in Catalan) seeks to minimize the impact of such course/program dropout factors (Lee \& Choi, 2011): course design and institutional support. Based on the employment of institutional learning analytics, it revised pathways and course design together with tenured professors (responsible for learning design) and part-time adjunct professors, providing also flexibility measures in the CA process (Meneses, Minguillón, González, \& Martínez-Aceituno, 2019). Enhancing tutorial quality, ESPRIA-trained advisory staff offers personalized support during the application and enrolment processes, helping first-year students to set realistic and achievable goals and to match their needs with their chosen course of study (Tresman, 2002), paying particular attention to student workload issues, capabilities, and time availability, while also detecting early risk situations so as to manage open entry. Such measures seek to avoid excessive student workload and help students achieve their goals in their first and second semesters, so they can be motivated to re-enrol in the following ones. However, ESPRIA's main goal is to help students adhere to and be successful in the CA process, especially in their first semester. Table 1 shows the numbers of academic staff and students involved in ESPRIA since its inception. A total of 16,479 students have participated in ESPRIA thus far.

Table 1: $\quad$ ESPRIA Intervention - Participants

\begin{tabular}{lrrrr}
\hline & Spring 2017 & Fall 2018 & Spring 2018 & Fall 2019 \\
\hline Programs & 6 & 8 & 9 & 10 \\
Courses & 51 & 69 & 78 & 78 \\
Tenured Professors & 46 & 63 & 73 & 76 \\
\hline Academic advisors & 145 & 267 & 243 & 312 \\
\hline Adjunct professors & 217 & 350 & 327 & 445 \\
\hline Students & 1,449 & 5,619 & 2,603 & 6,808 \\
\hline
\end{tabular}


Besides personalized support, ESPRIA offered first-year students two other measures. First, flexible enrolment packages, containing three courses that have non-overlapping calendars (i.e. submission deadlines) and with adjusted syllabus and workload so as to prevent work overload. Packages were designed taking into account learning analytics (enrolment patterns and course pass rates) and students' interests. Each degree offers three packages, each presenting a possible learning pathway, and students, guided by academic advisors, are free to choose between them and the number of courses they want to take. Second, flexibilizing the $C A$ process with some rescue alternatives: making up for a failed or non-submitted CA activity; creating a first, not graded CA activity to induce a smoother entry in the course; allowing delayed submission of assessments; among others.

In what follows we present the students' perceptions of such measures, their adequacy or risks, difficulties, and suggestions. This is part of an institutional evaluation of the project, focusing on its qualitative aspects from the students' perspective (professors and academic advisors will also be interviewed as part of such assessment), in order to inform this intervention and possible future ones, including in other open universities facing the same retention issues.

\section{Method}

Participants included eight first-year, fully online undergraduate UOC students who started their studies at UOC in September 2017 and were persisters (students who enrol for three consecutive semesters). Students were chosen according to the following criteria: age - non-traditional ( $\geqslant 25$ yearsold) or traditional; full-time (enrolled in more than 18 credits ECTS) or part-time, and gender (male or female). The study employed a qualitative, exploratory method, collecting data through semi-structured in-depth interviews (duration: one hour) following an interview protocol that explored the students' perceptions about ESPRIA measures. Students did not know that the measures were part of an institutional intervention. Interviews were transcribed and analysed following content analysis guidelines (Elo \& Kyngäs, 2008).

\section{Preliminary Results}

The preliminary results presented herein focus on the students' characteristics, depending on profiles, and their perceptions about ESPRIA measures. As here we have focused only on persistent students, results should be taken with caution. In this small sample, there were usually no significant gender differences.

Young (traditional) part-time students usually have a 30h work week, or else study two degrees at the same time; enrol in two or three courses per semester; have good time 
management skills; value the UOC system and its flexibility; and report some time conflict, especially during their first semester (when they are not familiar with the online system). They value especially the following intervention measures: course workload adjustment ("Yes, that would be good. So you can plan ahead and organize yourself" [Participant 1 P1]); and flexibilizing submission deadlines, particularly in the beginning of the semester, when they return from holidays and need more time to get accustomed to the routine again [P2].

Young full-time students do not work and enrol in 30 credits per semester; their underestimation of workload expectation leads to procrastination problems (especially for women), creating stress at the end of the semester (conflict with other commitments), but nevertheless they succeed. They would like more personal support (from advisors but especially from professors), and like the measure of flexibilizing submission deadlines but not for themselves, for they fear it would increase their procrastination: "I don't work, but for the people who do, or have kids, or unexpected situations, that would be great. Because in the end there's people who don't want high grades, they just want to complete the course" [P3]. "For a person like me, that would be no good. It'd probably feed my procrastination issues" [P4]. As they typically enrol in five courses per semester, they would like to have ESPRIA packages of five courses as well: "Yes, a package with five courses that have submission dates every two weeks, if they could provide me a leeway of two, at most three days between submissions, that would be great for me ... especially because it gives you time for your [personal] things" [P3]. One student valued course workload adjustment ("That's what you seek, right?, to adjust that. Then you can plan your activities better" [P3]), but the other perceived it negatively: "To adjust all the courses would perhaps make them more boring. I don't know" [P4]. They would like more information on the degree and online system before starting their studies; and not having group assignments (which take away the independence to which they are used).

Older, non-traditional part-time students typically enrol in 12 credits per semester and have full-time jobs; when they start their studies, it takes them a whole semester to get used to the open, online system. Their expectations are realistic, but when they enrol in more than two or three courses, they end up facing (time-related) problems. They value the flexibility and self-regulation of $\mathrm{OHE}$ and are very happy with academic advising (especially because of their lack of experience with $\mathrm{OHE}$ and the fast replies of advisors to their doubts or demands). Flexibilizing submission deadlines is perceived as having both positive and negative sides: "If you increase flexibility, sure, you will have lower grades and the student will be more relaxed, and will let work aside a bit more, and if he thinks he will get a low grade, then 'well, I'll submit it soon'. It feeds procrastination” [P5]. Regarding workload adjustment, students would like more details and more adjustment: "How much 
it'd cost, in terms of time and dedication, to take such course" [P5]. "Yes, because then you can have an estimation, so you can be bold and think, 'I'll enroll in three courses'" (instead of two) [P6]. They like the non-overlapping submission measure in ESPRIA packages: "Yes, because then it's smoother, you can plan yourself" [P6]. They also demand measures to give them a sense of community, something that changes their perception of cold online interactions: Skype videoconferences, or similar. "A face-to-face meeting with my advisor, like 'so explain to me your doubts', or... Because it is indeed a distance university. But in the end, we who are behind a computer screen, we're people" [P5].

Non-traditional full-time students live with parents or partner, do not work, and enrol in 30 credits per semester. They have very good time management skills and are adapted to the OHE system, valuing a lot its flexibility. They expected to work more than what was required of them, and do not present procrastination nor stress regarding time. They would like more personalized support as voicemail or similar measures. Regarding ESPRIA measures, they think the possibility of making up for failed submissions would be beneficial, but for other students: "Normally you have enough time to submit a graded activity. But it's true that, anything happens, like getting sick, or having to travel for a week, something like that, if you don't submit by the deadline you've lost it, and so that possibility of making up for submissions would be good" [P7]. Non-overlapping of submissions is also seen as a good measure, but mostly not for themselves (only in special cases). "There's enough time to submit the activities... But there are also people who indeed prefers more than a week [of time available to submit], so... it would be good. That will depend on the user [student]" [P7]. “There are some hard moments, when you have many submissions at the same time, and you're tired, you know?, and you are not in the same rhythm you were at the beginning of the semester, so it becomes a bit heavy. So I prefer submission dates [for different courses] to be in the same week, for example, Mondays, Wednesdays, and Fridays. One day at least between them. So I can dedicate myself to the other two [submissions]. If I had one submission per week, I wouldn't like it, because then I'd go crazy, every week you have this tension" [P8]. They think flexibilizing deadlines is a good measure. "It wouldn't induce myself to procrastinate, no, because I always try to get the highest grades” [P8].

\section{Conclusions}

As seen, each student profile experiences time in different manners, and has dissimilar time management skills, demands, and perceptions of needed support measures. Thus, treating the different profiles in the same way is not adequate, for they display different behaviours, demands, experiences, and strategies to succeed. However, for most students, time-related factors represent the major issue for persistence and continuance. The ideal 
would be to design and implement forms of support tailored to each profile, according to their specific demands. Almost all participants value online flexibility, but for some it also represents conflicting demands, especially the profiles who present more time-related problems (e.g. procrastination in full-time students). In this sense, for some profiles some measures (e.g. flexibilizing submission deadlines) would be good; but for other profiles (procrastinators, or the ones with very high expectations of personal performance), they would be counterproductive. The intervention measures described here should ideally be extended to full-time students - which is particularly difficult, given the difficulties inherent to flexibilizing submission dates and making them non-overlapping in five different courses.

Some common demands, which ESPRIA tries to fulfil, were seen in almost all profiles: more personalized feedback and mentorship and the possibility of making up for CA graded activities. Some demands are hardly feasible in an open University model: face-toface mentorship, synchronous advising, and so on. Misconceptions and unreal expectations may be diminished or transformed through providing more information on the reality of online studies before the first enrolment.

Therefore, future retention interventions in open universities should focus on the first academic year, especially the first semester (which presents the highest attrition rates), and be embedded in ampler interventions addressing situational, institutional, and personal factors: flexibility in continuous assessment; identifying and providing personalized support especially for at-risk students early on; targeted advice and orientation; and personalized course plans, especially for their first enrolment.

\section{References}

Ashby, A. (2004). Monitoring student retention in the Open University: Definition, measurement, interpretation and action. Open Learning, 19(1), 65-77. doi:10.1080/0268051042000177854

Bawa, P. (2016). Retention in online courses: Exploring issues and solutions - a literature review. SAGE Open, 6(1), 1-11. doi:10.1177/2158244015621777

Elo, S., \& Kyngäs, H. (2008). The qualitative content analysis process. Journal of Advanced Nursing, 62(1), 107-115. doi:10.1111/j.1365-2648.2007.04569.x

González, L., Minguillón, J., Martínez-Aceituno, J. A., \& Meneses, J. (2018). Institutional support to provide freshmen with flexible learning paths at course and semester level in open higher education. Proceedings 10th EDEN Research Workshop, Barcelona, pp. 348-354. Retrieved from https://proceedings.eden-online.org/wpcontent/uploads/2018/11/RW10_2018_Barcelona_Proceedings_ISSN.pdf 
Grau-Valldosera, J., Minguillón, J., \& Blasco-Moreno, A. (2018). Returning after taking a break in online distance higher education: From intention to effective re-enrolment. Interactive Learning Environments, 27(3), 307-323. doi:10.1080/10494820.2018.1470986

Hovdhaugen, E. (2015). Working while studying: The impact of term-time employment on dropout rates. $J$ Educ and Work, 28(6), 631-651. doi:10.1080/13639080.2013.869311

Korstange, R., Hall, J., Holcomb, J., \& Jackson, J. (2020). The online first-year experience: Defining and illustrating a new reality. Adult Learning. doi:10.1177/1045159519892680

Lee, Y., \& Choi, J. (2011). A review of online course dropout research: Implications for practice and future research. Educational Technology Research and Development, 59(5), 593-618. doi:10.1007/s11423-010-9177-y

McNeill, W. N. (2010). The time-use of distance learners: a study of international postgraduate students engaged in professional career development. (Doctoral dissertation). University of London, London, UK. Retrieved from http://discovery.ucl.ac.uk/10006518/

Meneses, J., Minguillón, J., González, L., \& Martínez-Aceituno, T. (2019). ESPRIA. Millora de l'Acompanyament dels Estudiants de Primer Any. Barcelona: Universitat Oberta de Catalunya. Retrieved from http://hdl.handle.net/10609/103166

Michinov, N., Brunot, S., Le Bohec, O., Juhel, J., \& Delaval, M. (2011). Procrastination, participation, and performance in online learning environments. Computers \& Education, 56(1), 243-252. doi:10.1016/j.compedu.2010.07.025

Muljana, P. S., \& Luo, T. (2019). Factors contributing to student retention in online learning and recommended strategies for improvement: A systematic literature review. Journal of Information Technology Education: Research, 18, 19-57, 2019. doi:10.28945/4182

Simpson, O. (2010). '22\% - can we do better?' - The CWP Retention literature review final report. London: Open University. Retrieved from http://www.ormondsimpson.com/USERIMAGES/Retention\%20literature\%20review. pdf

Slim, A., Heileman, G. L., Al-Doroubi, W., \& Abdallah, C. T. (2016). The impact of course enrolment sequences on student success". Proceedings of $30^{\text {th }}$ International Conference on Advanced Information Networking and Applications, Crans-Montana, Switzerland. doi:10.1109/AINA.2016.140 
Soffer, T., Kahan, T., \& Nachmias, R. (2019). Patterns of students' utilization of flexibility in online academic courses and their relation to course achievement. International Review of Research in Open and Distributed Learning, 20(3). doi:10.19173/irrodl.v20i4.3949

Tresman, S. (2002). Towards a strategy for improved student retention in programmes of open, distance education: A case study from the Open University UK. Int Rev Res Open Distr Learning, 3(1). Retrieved from http://www.irrodl.org/index.php/irrodl/article/download/75/544

Xavier, M., \& Meneses, J. (2018). The time factor in studies on dropout in online higher education: Initial review of the literature and future approaches. Proceedings $10^{\text {th }}$ EDEN Research Workshop, Barcelona, 361-367. Retrieved from https://proceedings.eden-online.org/wpcontent/uploads/2018/11/RW10_2018_Barcelona_Proceedings_ISSN.pdf

Yukselturk, E., \& Inan, F. A. (2006). Examining the factors affecting student dropout in an online learning environment. Turk. online J. Distance Educ., 7(3), 76-88. Retrieved from https://files.eric.ed.gov/fulltext/ED494345.pdf

\section{Acknowledgment}

With the support of a doctoral grant from the Universitat Oberta de Catalunya (UOC). 